\title{
Multiple defects of both hepatic and peripheral intracellular glucose processing contribute to the hyperglycaemia of NIDDM
}

\author{
A. Vaag $^{1}$, F. Alford ${ }^{1,2}$, F. L. Henriksen ${ }^{1}$, M. Christopher ${ }^{2}$, H. Beck-Nielsen ${ }^{1}$ \\ ${ }^{1}$ Odense University Hospital, Department of Endocrinology and Internal Medicine M, Odense, Denmark \\ ${ }^{2}$ St. Vincent's Hospital, Department of Endocrinology and Diabetes, Fitzroy, Victoria, Australia
}

Summary Non-insulin-dependent diabetic (NIDDM) patients were studied during a modified euglycaemic state when fasting hyperglycaemia was normalized by a prior ( -210 to $-150 \mathrm{~min})$ - and later withdrawn $(-150-0 \mathrm{~min})-$ intravenous insulin infusion. Glucose metabolism was assessed in NIDDM patients $(n=10)$ and matched control subjects $(n=10)$ using tritiated glucose turnover rates, indirect calorimetry and skeletal muscle glycogen synthase activity determinations. Total and non-oxidative exogenous glycolytic flux rates were measured using appearance rates of tritiated water. $\mathrm{A}+180 \mathrm{~min}$ euglycaemic hyperinsulinaemic $\left(40 \mathrm{mU} \cdot \mathrm{m}^{-2} \cdot \mathrm{min}^{-1}\right)$ clamp was performed to determine the insulin responsiveness of the various metabolic pathways. Plasma glucose concentration increased spontaneously during baseline measurements in the NIDDM patients $(-120$ to $0 \mathrm{~min}: 4.8 \pm 0.3$ to $7.0 \pm 0.3 \mathrm{mmol} / \mathrm{l} ; p<0.01$ ), and was primarily due to an elevated rate of hepatic glucose production $(3.16 \pm 0.13$ vs $2.51 \pm 0.16 \mathrm{mg} \cdot \mathrm{kg}$ $\left.\mathrm{FFM}^{-1} \cdot \min ^{-1} ; p<0.01\right)$. In the NIDDM subjects baseline glucose oxidation was decreased $\left(0.92 \pm 0.17\right.$ vs $1.33 \pm 0.14 \mathrm{mg} \cdot \mathrm{kg} \mathrm{FFM}^{-1} \cdot \mathrm{min}^{-1}$; $p<0.01)$ in the presence of a normal rate of total exogenous glycolytic flux and skeletal muscle glycogen synthase activity. The simultaneous finding of an in- creased lipid oxidation rate $(1.95 \pm 0.13$ vs $\left.1.61 \pm 0.07 \mathrm{mg} \cdot \mathrm{kg} \mathrm{FFM}-1 \cdot \mathrm{min}^{-1} ; p=0.05\right)$ and increased plasma lactate concentrations $(0.86 \pm 0.05$ vs $0.66 \pm 0.03 \mathrm{mmol} / \mathrm{l} ; p=0.01$ ) are consistent with a role for both the glucose-fatty acid cycle and the Cori cycle in the maintenance and development of fasting hyperglycaemia in NIDDM during decompensation. Insulin resistance was demonstrated during the hyperinsulinaemic clamp in the NIDDM patients with a decrease in the major peripheral pathways of intracellular glucose metabolism (oxidation, storage and muscle glycogen synthase activity), but not in the pathway of non-oxidative glycolytic flux which was not completely suppressed during insulin infusion in the NIDDM patients $(0.55 \pm 0.15 \mathrm{mg} \cdot \mathrm{kg}$ $\mathrm{FFM}^{-1} \cdot \min ^{-1} ; \quad p<0.05$ vs 0 ; control subjects: $0.17 \pm 0.29$; NS vs 0 ). Thus, these data also indicate that the defect(s) of peripheral (skeletal muscle) glucose processing in NIDDM goes beyond the site of glucose transport across the cell membrane. [Diabetologia (1995) 38: $326-336]$

Key words Hepatic glucose production, glucose fatty acid cycle, Cori cycle, muscle glucose metabolism, glycogen synthase.
Received: 4 May 1994 and in revised form: 19 August 1994

Corresponding author: Dr. A. Vaag, Department of Endocrinology and Internal Medicine M, Odense University Hospital, Sdr. Boulevard, DK-5000, Odense C, Denmark

Abbreviations: NIDDM, Non-insulin-dependent diabetes mellitus; FFM, fat free mass; HGP, hepatic glucose production; $\mathbf{R}_{\mathrm{d}}$, peripheral glucose disposal (uptake) rate; G6P, glucose 6-phosphate; UDPG, uridine diphosphate glucose; FV, fractional velocity.
The cause and development of hyperglycaemia (fasting and postprandial) in patients with non-insulin-dependent diabetes mellitus (NIDDM) is due to an overproduction of glucose by the liver and a decreased uptake of glucose by peripheral tissues, especially by the skeletal muscles. However, the relative contributions of overproduction of glucose by the liver vs decreased peripheral uptake of glucose is currently being debated [1-3] and depends on the de- 
gree of glucose intolerance present [1-3], the methodology employed to measure glucose turnover $[1,4]$, and the metabolic state of the patient at the time of study $[4,5]$. In addition, it is now realised that fasting hyperglycaemia in NIDDM patients represents an "endogenous compensated state" [3-5], whereby the hyperglycaemia per se is attempting to promote "compensation" of glucose turnover through its stimulatory effect on the pancreatic insulin secretion [6]; enhancing effect on uptake of glucose in peripheral tissues through a mass action [7]; and suppressing effect on output of glucose from the liver [8]. Consequently, data pertaining to the functional state of the various factors included in the classic "triumvirate" during the "compensated hyperglycaemic state" may be different from those obtained during iatrogenicinduced euglycaemia. Knowledge about both the "hyperglycaemic compensated" and euglycaemic states is essential to our understanding of those factors (liver vs periphery) involved in the day-to-day euglycaemic-hyperglycaemic variations which occur normally in NIDDM subjects. The first aim of the present investigation was therefore to study glucose metabolism in fasting NIDDM patients during a modified "basal euglycaemic state". This was achieved by reducing the elevated fasting plasma glucose concentration to normal fasting levels by a prior intravenous insulin infusion, which was withdrawn at $-150 \mathrm{~min}$ in order to ensure that the influence of the prior insulin infusion (per se) on glucose metabolism had totally dissipated [9].

The second aim of these studies was to explore the impact of the various in vivo sites (peripheral vs hepatic) and in vivo partitioning of glucose metabolism down its various metabolic pathways (glycolysis, oxidation, non-oxidative glycolytic flux and glucose storage) during the decompensated euglycaemic state. To this end, the NIDDM subjects were studied basally 30 to $150 \mathrm{~min}$ after insulin withdrawal - and during physiologic hyperinsulinaemia (clamp) with measurements of hepatic glucose production (HGP), and peripheral glucose disposal $\left(\mathrm{R}_{\mathrm{d}}\right)$ employing $3-{ }^{3} \mathrm{H}$-glucose infusions; exogenous in vivo glycolytic flux and glucose storage rates employing the accumulation of tritiated water $\left({ }^{3} \mathrm{H}_{2} \mathrm{O}\right)$; and glucose oxidation, lipid oxidation and non-oxidative glycolytic flux rates using a combination of conventional indirect calorimetry with the above tracer techniques [10-13]. The data were compared to a carefully age-, sex- and weight-matched control group studied in the fasting euglycaemic state and during similar hyperinsulinaemia. Because of the importance and potential abnormalities in the enzyme glycogen synthase in skeletal muscle of NIDDM and pre-diabetic relatives of NIDDM patients [14-19], all studies examined glycogen synthase activities in skeletal muscle biopsies taken basally and during hyperinsulinaemia.
Table 1. Clinical and basal biochemical characteristics of the study subjects

\begin{tabular}{|c|c|c|c|}
\hline & NIDDM & $\begin{array}{l}\text { Control } \\
\text { subjects }\end{array}$ & $P$-value \\
\hline$n$ (male/female) & $10(6 / 4)$ & $10(5 / 5)$ & NS \\
\hline Age (years) & $62 \pm 3$ & $59 \pm 2$ & NS \\
\hline Weight (kg) & $82 \pm 4$ & $77 \pm 3$ & NS \\
\hline Height (cm) & $169 \pm 4$ & $168 \pm 3$ & NS \\
\hline $\mathrm{BMI}\left(\mathrm{kg} / \mathrm{m}^{2}\right)$ & $28.6 \pm 0.9$ & $27.3 \pm 0.8$ & NS \\
\hline Waist/hip ratio & $0.98 \pm 0.02$ & $0.90 \pm 0.04$ & $=0.05$ \\
\hline Body fat (kg) & $25.1 \pm 2.0$ & $26.6 \pm 2.4$ & NS \\
\hline Fat-free mass $(\mathrm{kg})$ & $56.8 \pm 4.1$ & $53.1 \pm 3.8$ & NS \\
\hline $\begin{array}{l}\text { Duration of diabetes } \\
\text { (years) }\end{array}$ & $8 \pm 3$ & - & - \\
\hline $\begin{array}{l}\text { Fasting plasma glucose } \\
\text { concentration }(\mathrm{mmol} / \mathrm{l})\end{array}$ & $10.9 \pm 1.3$ & $5.5 \pm 0.2$ & $<0.001$ \\
\hline $\begin{array}{l}\text { Fasting plasma insulin } \\
\text { concentration }(\mu \mathrm{U} / \mathrm{ml})\end{array}$ & $12.7 \pm 1.8$ & $7.4 \pm 1.0$ & $<0.01$ \\
\hline $\begin{array}{l}\text { Plasma triglyceride } \\
\text { concentration }(\mathrm{mmol} / \mathrm{l})\end{array}$ & $1.75 \pm 0.34$ & $1.37 \pm 0.25$ & NS \\
\hline $\begin{array}{l}\text { Plasma cholesterol } \\
\text { concentration }(\mathrm{mmol} / \mathrm{l})\end{array}$ & $5.46 \pm 0.36$ & $5.96 \pm 0.39$ & NS \\
\hline $\begin{array}{l}\text { Glycated haemoglobin } \\
\left(\mathrm{HbA}_{10}, \%\right)\end{array}$ & $8.5 \pm 0.1$ & $6.1 \pm 0.2$ & $<0.001$ \\
\hline
\end{tabular}

\section{Subjects and methods}

Subjects. Ten NIDDM patients and ten age-, sex-, body-weight and -composition-matched control subjects participated in the study (Table 1). The waist/hip ratio was higher in the NIDDM subjects (Table 1). Four of the diabetic patients were treated with diet alone, five with oral hypoglycaemic agents (sulphonylureas and/or metformin), and one with insulin. The latter patient had been treated with insulin for only 6 months with a duration of diabetes of 9 years, a BMI of $30.3 \mathrm{~kg} / \mathrm{m}^{2}$, and was aged 62 years at the time when diabetes was diagnosed. Three of the diabetic patients were treated for hypertension, one with thiazide diuretics, one with loop diuretics, and one with combined loop diuretics and potassium-sparing diuretics. None of the control subjects received any kind of medication. All medication was withdrawn in the treated diabetic patients at least $72 \mathrm{~h}$ prior to studies. All measurements of glucose metabolism, including in vivo insulin action, were similar in hypertensive and normotensive NIDDM patients. Plasma glucose concentrations and blood pressures were measured in patients after the withdrawal of treatment (Table 1). Besides diabetes and hypertension (blood pressures; mean SEM; NIDDM vs control subjects: $146 \pm 8 / 80 \pm 5$ vs $137 \pm 5 / 84 \pm 2 \mathrm{~mm} \mathrm{hg}$, NS), none of the subjects had any clinical evidence of endocrine, cardiac, hepatic or renal disease. Subjects were not undertaking arduous exercise, and all subjects were instructed to avoid excessive physical exercise for at least 2 days before clamp studies. None of the control subjects had any family history of diabetes mellitus. Studies in the NIDDM patients and control subjects were run in parallel to eliminate time and season variation in any of the measurements. Informed consent was obtained from all subjects. The protocol was approved by the regional ethical committee and the procedures were performed according to the principles of the Helsinki Declaration. 
Plasma glucose $(\mathrm{mmol} / \mathrm{l})$

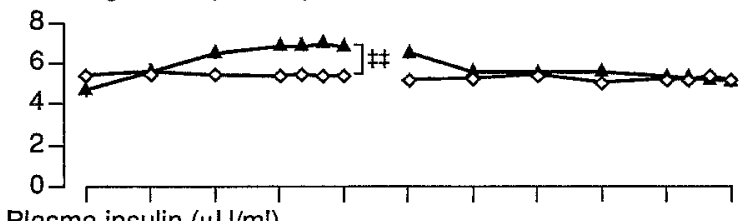

Plasma insulin $(\mu \mathrm{U} / \mathrm{ml})$

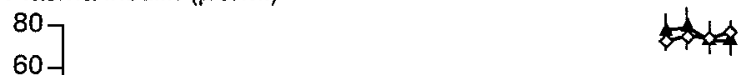

$40-$

20

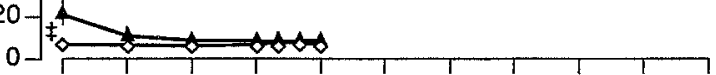

Plasma NEFA (mmol/l)

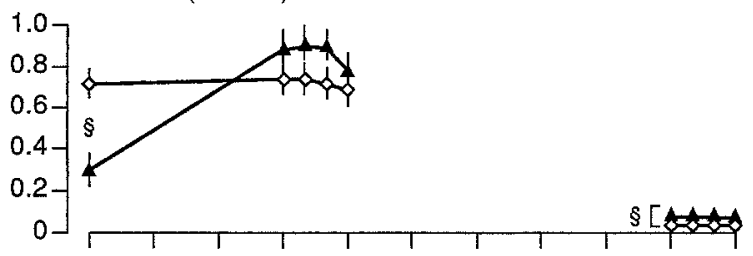

Plasma lactate $(\mathrm{mmol} / \mathrm{l})$

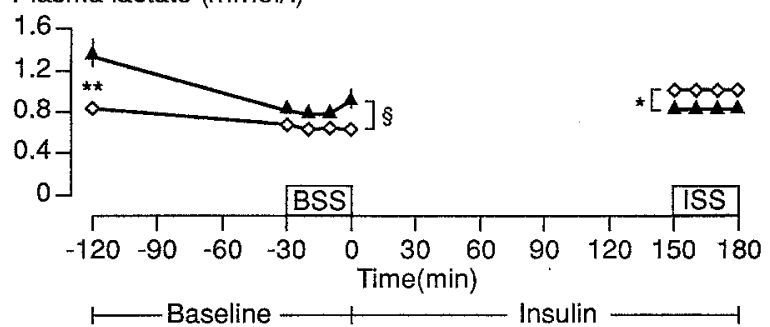

Fig. 1. Plasma glucose, insulin, lactate, and non-esterified fatty acid (NEFA) concentrations during studies. Data are the mean SEM of 10 NIDDM patients $(\boldsymbol{A})$ and 10 matched control subjects $(\diamond) . \quad{ }^{*} p<0.05 ; \quad{ }^{\ddagger} p<0.02 ; \quad{ }^{\S} p<0.01 ; \quad * * p<0.002 ;$ $\# p<0.001$. BSS, baseline isotopically steady-state or "equilibrium" periods; ISS, Insulin-stimulated steady-state periods

Baseline measurements. All studies were started at 07.30 hours after a 10-h overnight fast. A polyethylene catheter was inserted into an antecubital vein for infusion of test substances. Another polyethylene catheter was inserted into a contralateral wrist vein for blood sampling. This hand was placed and maintained in a heated plexiglass box to obtain arterialized venous blood [20]. Plasma glucose was normalized in the diabetic patients before each study by an intravenous insulin infusion given over a period of $46 \pm 7 \mathrm{~min}$ (mean $\pm \mathrm{SEM}$ ). The mean \pm SEM insulin dose given during this period was $8.3 \pm 1.7 \mathrm{IU}$ or $0.16 \pm 0.03 \mathrm{IU} / \mathrm{min}$. The insulin infusion was stopped when the plasma glucose concentration had declined to a mean of $6.3 \pm 0.3 \mathrm{mmol} / 1$, and a further period of $30 \mathrm{~min}$ elapsed while the plasma glucose concentration continued to decline to $4.8 \pm 0.3 \mathrm{mmol} / 1$, which was similar to the fasting plasma glucose concentration in the control subjects of $5.4 \pm 0.1 \mathrm{mmol} / \mathrm{l}$. This time point marked the initiation of each experiment (time $-120 \mathrm{~min}$ ), when the tracer bolus was given. None of the patients experienced any episodes of either clinical or chemical hypoglycaemia during these initial adjustments of the plasma glucose concentrations. Baseline measurements of glucose and lipid metabolism were performed during the pre-defined baseline "equilibrium" periods from -30$0 \mathrm{~min}$ (i.e. some $135 \mathrm{~min}$ after insulin infusion given to the NIDDM patients ceased and 60 min after plasma insulin levels were similar to basal control levels) (Fig. 1) when tracer equilibrium was anticipated (i.e. constant specific activities) (Fig. 2).
Specific activities

(cpm/mg glucose)

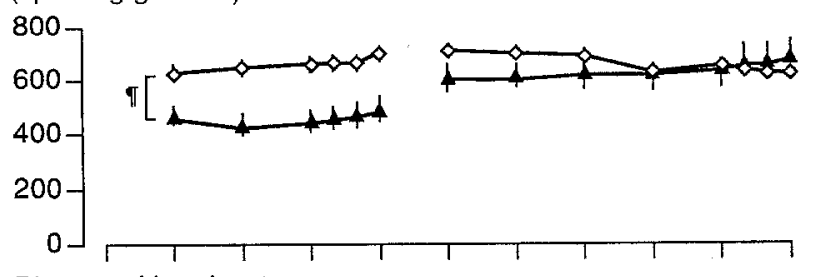

Plasma tritiated water

(cpm/ml plasma)

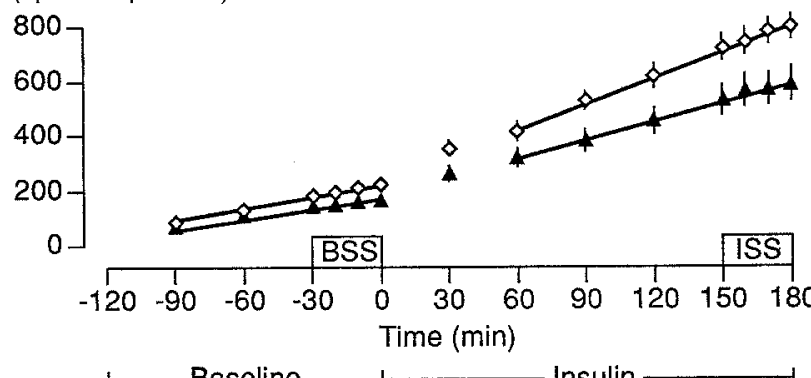

$\longmapsto$ Baseline $\longrightarrow$ Insulin $\longrightarrow$

Fig. 2. Plasma glucose specific activities ( $\mathrm{cpm} / \mathrm{mg}$ glucose) and
plasma tritiated water measurements $(\mathrm{cpm} / \mathrm{ml}$ plasma) during studies. Data are the mean \pm SEM of 10 NIDDM patients $(A)$ and 10 matched control subjects $(\diamond)$.,$p<0.005$; BSS, baseline isotopically steady-state or "equilibrium" periods; ISS, insulin-stimulated steady-state periods. Linearity of the increment of tritiated water radioactivity was obtained in NIDDM patients $\left(R^{2}=0.95 \pm 0.01\right)$ and control subjects $\left(R^{2}=0.95 \pm 0.01\right)$ from -90 to 0 min during baseline measurements, and in NIDDM patients $\left(R^{2}=0.96 \pm 0.01\right)$ and control subjects $\left(R^{2}=0.97 \pm 0.01\right)$ from +60 to +180 min during insulin infusion

Euglycaemic hyperinsulinaemic clamp. From 0 to $+180 \mathrm{~min}$ in sulin (Actrapid; Novo-Nordisk, Bagsvaerd, Denmark) was infused at a constant rate of $40 \mathrm{mU} \cdot \mathrm{m}^{-2} \cdot \mathrm{min}^{-1}$ in both NIDDM patients and control subjects. Plasma glucose concentration was maintained constant at euglycaemia using a variable glucose infusion mmol/1 (180 g/l) [21]. Plasma glucose concentration was monitored in arterialized blood every 5-10 min using an automated glucose oxidase method (Glucose Analyser 2; Beckman Instruments, Fullerton, Calif., USA). Measurements of insulin-stimulated glucose- and lipid turnover rates were performed from +150 to +180 min during clamps (i.e. pre-defined insulin-stimulated steady-state periods).

Tritiated glucose. The glucose clamp studies were combined with a primed $(22 \mu \mathrm{Ci})$, continuous $(0.22 \mu \mathrm{Ci} / \mathrm{min})$ infusion of 3- ${ }^{3} \mathrm{H}$-glucose (New England Nuclear, Boston, Mass., USA). Similar tracer priming doses were given to NIDDM patients and control subjects due to the prior normalisation of fasting hyperglycaemia in the NIDDM patients (i.e. similar plasma glucose contrations at the time point -120 min when tracer boli were given) [4]. The radiochemical purity of the tracer was $100 \%$ as determined by HPLC. In order to ensure isotope equilibrium, the continuous infusion of $3{ }^{3} \mathrm{H}$-glucose was initiated at $-120 \mathrm{~min}$, and continued throughout to the $+180 \mathrm{~min}$ period of insulin infusion. Furthermore, to obtain constant specific activity during insulin infusion, tritiated glucose was added to the infused cold glucose $(100 \mu \mathrm{Ci} / 500 \mathrm{ml} 18 \%$ glucose $)$ [22]. Blood samples were drawn in fluoride treated tubes every $10 \mathrm{~min}$ during both of the 30-min "equilibrium" or "steady-state" periods for the determination of plasma glucose, plasma $3-{ }^{3} \mathrm{H}$-glucose- and plasma $3-{ }^{3} \mathrm{H}$-water activity. During the rest of the study period, plasma glucose, plasma $3-{ }^{3} \mathrm{H}$-glu- 
cose, and plasma $3-{ }^{3} \mathrm{H}$-water activity was measured every $30 \mathrm{~min}$. Plasma $3-{ }^{3} \mathrm{H}$-water activity was determined by the subtraction of tritium counts of the evaporated $0.5 \mathrm{ml}$ plasma sample from tritium counts obtained from a non-evaporated $0.5 \mathrm{ml}$ plasma sample [10-11].

Indirect calorimetry. Indirect calorimetry was performed using a computerized flowthrough canopy gas analyser system (Deltatrac, Datex, Helsinki, Finland). Briefly, air is suctioned at a rate of 40 litres per min through a canopy placed over the head of the subject. Samples of inspired and expired air are analysed for oxygen concentration using a paramagnetic differential oxygen sensor and for carbon dioxide using an infrared carbon dioxide sensor. Signals from the gas analysers are processed by the computer and oxygen consumption and carbon dioxide production are calculated and recorded each min $[5,7,14,16]$. After an equilibration period of $10 \mathrm{~min}$, the average gas exchange rates recorded over the two final $30 \mathrm{~min}$ "equilibrium" or "steady-state" periods ( -30 to $0 \mathrm{~min}$ and +150 to $+180 \mathrm{~min}$ ) were used to calculate rates of glucose oxidation, lipid oxidation and energy expenditure as previously described $[23,24]$. The protein oxidation rate was estimated from urinary urea nitrogen excretion $(1 \mathrm{~g}$ nitrogen $=6.25 \mathrm{~g}$ protein) and corrected for changes in pool size [25].

Muscle biopsy. Muscle biopsies were performed using a modified Bergström needle (including suction) under local anaesthesia at the time points $0 \mathrm{~min}$ (baseline) and $+180 \mathrm{~min}$ (insulin-stimulated). The biopsies were rapidly (within 10-15 s) frozen and stored in liquid nitrogen for later analysis. Before the biochemical analysis the muscle samples were freeze-dried and dissected free of visible connective tissue, fat and blood $[5,7,14,16]$.

Calculations. Glucose turnover rates (hepatic glucose production (HGP) and total peripheral glucose disposal) were calculated at 10-min intervals during the pre-defined "equilibrium" or "steady-state" periods using Steele's non-steady-state equations [26]. Thus, although "steady-state" was obtained for all measurements of tritiated glucose specific activities in all subjects (Fig.2), the NIDDM patients were studied under a metabolic non-steady-state "equilibrium" baseline situation with a spontaneously increasing plasma glucose concentration (Fig. 1). In the calculations of glucose turnover rates, the distribution volume of glucose was taken as $200 \mathrm{ml} / \mathrm{kg}$ body weight and the pool fraction as 0.65 [27]. It should be noted that, using the assumptions included in Steele's non-steady-state equations for the determination of peripheral glucose uptake rates during a metabolic non-steady-state situation [26], the rates of peripheral glucose uptake may theoretically be less accurately estimated compared with the rates of HGP. Residual HGP during clamp studies was calculated by subtracting the rate of exogenously infused glucose from the rate of appearance of $3-{ }^{3} \mathrm{H}$-glucose. Non-oxidative glucose metabolism was calculated as the difference between total body glucose utilization (as determined from the rate of disappearance of $3-{ }^{3} \mathrm{H}$ glucose) and the rate of glucose oxidation (as determined by indirect calorimetry).

Exogenous glycolytic flux rate was calculated from the in crement per unit time in plasma tritiated water radioactivity $\left(\mathrm{cpm} \cdot \mathrm{ml}^{-1} \cdot \mathrm{min}^{-1}\right)$, as described previously in both animals $[10,11]$ and man $[12,13]$. Briefly, this measurement is based on the knowledge that essentially all of tritium in the C-3 position of the glucose molecule is lost in water at the triose-isomerase step during the glycolytic process [10, 12, 28-31], and therefore representing the amount of glucose taken up by the cell which is either oxidized or released as lactate. Thus, although tritium may also be released during fructose 6-phos- phate cycling and/or pentose phosphate cycling, it is well established that the latter pathways contribute to only a small percentage of the total glucose turnover [29-31]. Linearity of the increment of tritiated water radioactivity was obtained in NIDDM patients $\left(R^{2}=0.95 \pm 0.01\right)$ and control subjects $\left(R^{2}=0.95 \pm 0.01\right)$ from -90 to 0 min during baseline measurements, and in NIDDM patients $\left(R^{2}=0.96 \pm 0.01\right)$ and control subjects $\left(R^{2}=0.97 \pm 0.01\right)$ from +60 to +180 min during insulin infusion (Fig. 2). In these calculations, plasma water was assumed to be $93 \%$ of the total plasma volume [10], and the total body water content was calculated in each subject using the bioimpedance method [32]. During the hyperinsulinaemic clamp non-oxidative glycolytic flux was calculated by the subtraction of whole body glucose oxidation (as determined from indirect calorimetry measurements) from the rates of exogenous glycolytic flux measurements, and exogenous glucose storage was calculated as the difference between total peripheral glucose disposal (as determined from tritiated glucose measurements) and exogenous glycolytic flux (as determined from tritiated water measurements).

For our calculations of the exogenous glycolytic flux rate we use the specific activities of $3-{ }^{3} \mathrm{H}$-glucose in plasma (extracellular space) and therefore measure the amount of extracellularly derived glucose that passes through the triose-isomerase step. Thus, the parameter "exogenous glucose storage" separates that fraction of total in vivo glucose uptake rate (derived from $3-{ }^{3} \mathrm{H}$-glucose) which does not appear as $3-{ }^{3} \mathrm{H}$-water (exogenous glycolytic flux rate). It should be noted that when insulin levels are low basally (in the fasting state) there is no net glucose (glycogen) storage. Thus, the rate of endogenous glycogenolysis (from unlabelled glycogen) during low plasma insulin levels (baseline determinations) is probably similar to (or higher than) the measured rate of so called basal "exogenous glucose storage". In turn, this means that an unknown, but significant amount of endogenous glycolytic flux rate (derived from glycogenolysis) should be added to the exogenous glycolytic flux rate in order to determine the total rate of whole body glycolytic flux. However, during the high insulin levels, when the net glucose (glycogen) storage rates are positive, the above considerations are quantitatively much less important with endogenous muscle glycogenolysis being suppressed by more than $90 \%$ [13]. In addition, under hyperinsulinaemic conditions glucose oxidation as determined by indirect calorimetry or directly from measurement of ${ }^{14} \mathrm{CO}_{2}$ production in expired air are similar [33]. Thus, under these latter conditions, a relative estimation of glucose storage and nonoxidative glycolytic flux can be obtained [10-13]. In contrast, it is not possible to obtain accurate estimates of non-oxidative glycolytic flux rates under low insulin basal conditions because of the significant portion of total endogenous glycolysis which is not measured with the current technique (see above). This means that under basal conditions, no measure of nonoxidative glycolytic flux can be given. Furthermore, the difference between total basal glucose utilization (derived from 3 ${ }^{3} \mathrm{H}$-glucose and ${ }^{3} \mathrm{H}_{2} \mathrm{O}$ generated glycolytic flux i. e. "basal exogenous glucose storage") does not represent "net glucose storage" but most probably glycogen turnover, in particular indirectly endogenous glycogenolysis.

Glucose and lipid metabolism data were expressed as $\mathrm{mg}$ per $\mathrm{kg}$ FFM (fat free mass) per min, and are presented throughout the paper as the mean values calculated over the two 30 min steady-state periods. Total body fat content (and thus FFM) was measured using the bioimpedance method [31].

Glycogen synthase activity. Extraction of muscle samples and assays for glycogen synthase were performed as we previously described $[5,7,14,16,34]$ by a modification of the method of 
Thomas et al. [35]. Glycogen synthase activity was assayed without adding G6P, in the presence of a near-physiological concentration of glucose 6-phosphate (G6P) $(0.1 \mathrm{mmol} / \mathrm{l})$ and in the presence of a high concentration of G6P $(10 \mathrm{mmol} / \mathrm{l})$. The total concentration of uridine diphosphate glucose $\left({ }^{14} \mathrm{C}\right.$ UDPG + cold UDPG) in the reaction mixture was $0.31 \mathrm{mmol} /$ 1. Furthermore, glycogen synthase activities were measured in all subjects at a G6P concentration of $10 \mathrm{mmol} / \mathrm{l}$ and a total UDPG concentration of $5 \mathrm{mmol} / \mathrm{l}$ in order to determine the total enzyme activity. Glycogen synthase activity was expressed as nanomoles of UDPG incorporated into glycogen per minute per milligram extract protein. Fractional velocities (FV) were calculated as the ratio between glycogen synthase activities assayed at $0 \mathrm{mmol} / 1 \mathrm{G} 6 \mathrm{P}$ and $10 \mathrm{mmol} / \mathrm{l} \mathrm{G} 6 \mathrm{P}$ (FV 0.0$)$ and at $0.1 \mathrm{mmol} / \mathrm{l} \mathrm{G} 6 \mathrm{P}$ and $10 \mathrm{mmol} / \mathrm{l} \mathrm{G} 6 \mathrm{P}$ (FV 0.1).

Analytical determinations. Glucose in plasma was determined using an automated glucose oxidase method (Glucose Analyser 2; Beckman Instruments, Fullerton, Calif., USA). Tritiated glucose activity was measured as described by Hother-Nielsen and Beck-Nielsen [4]. Plasma insulin concentrations were measured using a double-antibody radioimmunological method (Pharmacia Diagnostics AB, Uppsala, Sweden). Nonesterified fatty acids (NEFA) in plasma were determined by the method of Itaya and Michio [36], and plasma lactate concentrations were measured using the method of Passonneau [37]. Plasma concentrations of glucose, insulin and NEFA were measured every $10 \mathrm{~min}$ during both steady-state periods. $\mathrm{HbA}_{1 \mathrm{c}}$ was measured by high performance liquid chromatography (normal range 5.4-7.4\%).

\section{Statistical analysis}

Non-parametric statistical methods (Wilcoxon test for paired data, Mann-Whitney test for unpaired data, and Spearman's rho $(R)$ for correlation analysis) were employed in analysis of data. $p$ values equal to or less than 0.05 were considered significant. Data in text and figures are presented as the mean \pm SEM.

\section{Results}

The age-, sex- and BMI-matched NIDDM patients had higher mean fasting plasma glucose- and insulin concentrations prior to the commencement of the insulin infusion compared with the fasting control subjects (Table 1). However, plasma glucose concentrations were similar in diabetic and control subjects 30 min after the withdrawal of the insulin infusion at the initiation of the baseline period (time $-120 \mathrm{~min}$; plasma glucose $4.8 \pm 0.3$ vs $5.4 \pm 0.1$; NS) (Fig. 1). During the -120 to $0 \mathrm{~min}$ baseline period of insulin withdrawal the plasma glucose concentrations were constantly increasing in the diabetic patients (time 120 vs 0 min; plasma glucose $4.8 \pm 0.3$ vs $7.0 \pm 0.3$; $p<0.01$ ) (Fig. 1), whereas they remained constant in the control subjects (time -120 vs 0 min; plasma glucose: $5.4 \pm 0.1$ vs $5.4 \pm 0.2$; NS). Thus, plasma glucose concentrations were significantly higher in the diabetic patients during baseline "steady-state" or "equilibrium" measurements of glucose and lipid turnover rates (time $-30-0 \mathrm{~min}$; plasma control 7.0 \pm 0.3 vs $4.4 \pm 0.2 ; p<0.001$ ) (Fig. 1 ). However, it should be noted that plasma glucose concentrations were still significantly lower during the insulin-withdrawn baseline "equilibrium" period compared with the fasting "compensated" hyperglycaemic state (plasma control $7.0 \pm 0.3$ vs $10.9 \pm 1.3 \mathrm{mmol} / 1 ; p<0.001$ ).

Plasma insulin concentrations were significantly higher in the NIDDM patients at the start of the baseline period (time $-120 \mathrm{~min} ; 22.8 \pm 6.2$ vs $7.6 \pm 1.0 \mu \mathrm{U} / \mathrm{ml} ; p<0.02$ ), but by $-90 \mathrm{~min}$ insulin levels were similar in NIDDM and control subjects (Fig.1). Thus, when measurements of glucose and lipid turnover rates were performed (i.e. -30 to $0 \mathrm{~min}$ ), no significant difference in plasma insulin concentrations was detected between the groups. Plasma insulin concentrations were somewhat lower in 9 of the 10 NIDDM patients during the insulinwithdrawn baseline "equilibrium" period compared with the "compensated" hyperglycaemic fasting state (mean \pm SEM: $10.1 \pm 2.8$ vs $12.7 \pm 1.8 \mu \mathrm{U} / \mathrm{ml}$; NS $(p<0.1)$ ). Plasma glucose and insulin concentrations were similar in diabetic patients and control subjects at all time points during the hyperinsulinaemic clamp insulin infusion (Fig.1). Coefficients of variation for glucose and insulin concentrations during insulin clamp studies were similar for NIDDM patients and control subjects (glucose: $5 \pm 1$ vs $5 \pm 1 \%$; NS; and insulin: $8 \pm 2$ vs $5 \pm 1 \%$; NS).

Plasma non-esterified free fatty acid (NEFA) concentrations were lower in the diabetic patients at the initiation of the baseline period (time $-120 \mathrm{~min}$; $0.30 \pm 0.08$ vs $0.72 \pm 0.07 \mathrm{mmol} / \mathrm{l} ; p<0.01$ ) (Fig. 1 ). However, plasma NEFA concentrations appeared higher in the diabetic patients during "equilibrium" baseline determinations at -30 to $0 \mathrm{~min}(0.87 \pm 0.08$ vs $0.72 \pm 0.08 \mathrm{mmol} / \mathrm{l}$; NS) and were higher during insulin infusion $(0.09 \pm 0.02$ vs $0.04 \pm 0.01 ; p<0.01)$.

Plasma lactate concentrations were significantly higher in the diabetic patients at the initiation of the baseline period (time $-120 \mathrm{~min} ; 1.38 \pm 0.13$ vs $0.84 \pm 0.06 \mathrm{mmol} / 1 ; p<0.002$ ) (Fig. 1) and during the baseline "equilibrium" period (-30-0 min; $0.86 \pm$ 0.05 vs $0.66 \pm 0.03 ; p=0.01$ ) (Fig. 1 ), whereas during insulin clamp infusion, the plasma lactate concentrations were lower in the diabetic patients compared with control subjects $(0.86 \pm 0.05$ vs $1.03 \pm 0.06$; $p<0.05)$. Thus, in contrast to the diabetic patients, plasma lactate concentrations increased significantly during insulin infusion only in the control subjects $(0.65 \pm 0.03$ vs $1.03 \pm 0.06 ; p<0.01$ ) (Fig. 1 ).

Tritiated glucose specific activities and plasma tritiated water counts during studies are given in Fig. 2. Specific tritiated glucose activities were constant in both NIDDM patients and control subjects during almost the entire baseline period from -120 to $0 \mathrm{~min}$ and during the clamp insulin infusions from 0 to $+180 \mathrm{~min}$. Specific activities were significantly lower in the NIDDM patients at all time points during baseline measurements (mean values at $-90-0$ min: $462 \pm 42$ vs $655 \pm 30 \mathrm{cpm} / \mathrm{mg}$ glucose; $p<0.005$ ). The increase in plasma tritiated water was constant dur- 
Table 2. Glucose and lipid turnover rates during studies in NIDDM patients $(n=10)$ and matched control subjects $(n=10)$

\begin{tabular}{|c|c|c|c|c|}
\hline & & NIDDM & Control subjects & $p$-value \\
\hline Hepatic glucose production rate & $\begin{array}{l}\text { Baseline } \\
\text { Insulin }\end{array}$ & $\begin{array}{l}3.16 \pm 0.13 \\
0.51 \pm 0.18^{\mathrm{ac}}\end{array}$ & $\begin{array}{l}2.51 \pm 0.16 \\
0.24 \pm 0.27^{\mathrm{a}}\end{array}$ & $\begin{array}{l}<0.01 \\
\text { NS }\end{array}$ \\
\hline Total glucose uptake rate & $\begin{array}{l}\text { Baseline } \\
\text { Insulin }\end{array}$ & $\begin{array}{l}3.07 \pm 0.11 \\
5.33 \pm 0.80^{\mathrm{b}}\end{array}$ & $\begin{array}{r}2.51 \pm 0.16 \\
11.65 \pm 1.1^{\mathrm{a}}\end{array}$ & $\begin{array}{l}<0.01 \\
<0.001\end{array}$ \\
\hline Exogenous glycolytic flux rate & $\begin{array}{l}\text { Baseline } \\
\text { Insulin }\end{array}$ & $\begin{array}{l}1.98 \pm 0.07 \\
3.01 \pm 0.18^{\mathrm{a}}\end{array}$ & $\begin{array}{l}1.93 \pm 0.13 \\
4.03 \pm 0.19^{\mathrm{a}}\end{array}$ & $\begin{array}{l}\text { NS } \\
<0.01\end{array}$ \\
\hline Glucose oxidation rate & $\begin{array}{l}\text { Baseline } \\
\text { Insulin }\end{array}$ & $\begin{array}{l}0.92 \pm 0.17 \\
2.46 \pm 0.23^{\mathrm{a}}\end{array}$ & $\begin{array}{l}1.33 \pm 0.14 \\
3.86 \pm 0.29^{\mathrm{a}}\end{array}$ & $\begin{array}{l}<0.01 \\
<0.002\end{array}$ \\
\hline Non-oxidative glycolytic flux rate & $\begin{array}{l}\text { Baseline } \\
\text { Insulin }\end{array}$ & $\overline{0} .55 \pm 0.15^{\mathrm{c}}$ & $\overline{0} .17 \pm 0.29$ & $\begin{array}{l}- \\
\mathrm{NS}\end{array}$ \\
\hline Non-oxidative glucose uptake rate & $\begin{array}{l}\text { Baseline } \\
\text { Insulin }\end{array}$ & $\begin{array}{l}2.15 \pm 0.17 \\
2.66 \pm 0.77\end{array}$ & $\begin{array}{l}1.18 \pm 0.20 \\
7.79 \pm 1.07^{\mathrm{a}}\end{array}$ & $\begin{array}{l}<0.005 \\
<0.005\end{array}$ \\
\hline Exogenous glucose storage rate & $\begin{array}{l}\text { Baseline } \\
\text { Insulin }\end{array}$ & $\begin{array}{l}1.09 \pm 0.13 \\
2.11 \pm 0.82\end{array}$ & $\begin{array}{l}0.58 \pm 0.19 \\
7.62 \pm 0.99^{\mathrm{a}}\end{array}$ & $\begin{array}{l}\text { NS } \\
<0.002\end{array}$ \\
\hline Lipid oxidation rate & $\begin{array}{l}\text { Baseline } \\
\text { Insulin }\end{array}$ & $\begin{array}{l}1.95 \pm 0.13 \\
1.19 \pm 0.13^{\mathrm{a}}\end{array}$ & $\begin{array}{l}1.61 \pm 0.07 \\
0.68 \pm 0.08^{\mathrm{a}}\end{array}$ & $\begin{array}{r}0.05 \\
<0.01\end{array}$ \\
\hline
\end{tabular}

Baseline values in the NIDDM patients were measured during a 30 -min equilibrium and isotopically steady-state period 120 to $150 \mathrm{~min}$ after the withdrawal of a prior i.v. insulin infusion given in order to normalize the plasma glucose concentration. Baseline values in the control subjects are measured in the fasting state, and insulin stimulated values in both NIDDM pa-

ing baseline determinations from $-90-0 \mathrm{~min}$ in NIDDM patients (Fig. 2) (see also Methods section).

Hepatic glucose production was significantly elevated in the diabetic patients during baseline "equilibrium" measurements (-30-0 $\mathrm{min})$ (Table 2$)$, as indicated above by the lower specific activities. The slightly higher rate of HGP in the diabetic patients during the clamp insulin infusion did not reach statistical significance. However, in contrast to the control subjects, HGP was significantly different from zero in the diabetic patients during clamp insulin infusion (Table 2). Total peripheral glucose uptake was significantly elevated in the NIDDM patients during baseline "equilibrium" measurements, and was markedly decreased during the clamp insulin infusion period (Table 2).

The rate of exogenous glycolytic flux was similar in diabetic patients and control subjects during "equilibrium" baseline (-30 to $0 \mathrm{~min}$ ) measurements, but was significantly decreased in diabetic patients during insulin infusion (Table 2). In contrast, glucose oxidation was significantly lower during the baseline $(-30$ to $0 \mathrm{~min})$ and insulin clamp period in the diabetic group (Table 2). Lipid oxidation rates were significantly higher in NIDDM patients compared with control subjects during both baseline "equilibrium" and insulin clamp periods (Table 2).

The rates of non-oxidative glycolytic flux were not significantly different from control subjects during insulin infusion (Table 2). However, in contrast to the control subjects, the non-oxidative glycolytic flux rate in the diabetic patients was not completely suppressed by insulin (significantly higher than zero) (Table 2). tients and control subjects during the final 30-min steady-state period of $\mathrm{a}+180 \mathrm{~min} 40 \mathrm{mU} \cdot \mathrm{m}^{-2} \cdot \mathrm{min}^{-1}$ hyperinsulinaemic and euglycaemic clamp. All data are expressed as $\mathrm{mg} \cdot \mathrm{kg}$ $\mathrm{FFM}^{-1} \cdot \mathrm{min}^{-1}$. Data are mean \pm SEM. ${ }^{\mathrm{a}} p<0.002$ vs baseline determinations; $p<0.02$ vs baseline determinations; $p<0.05$ vs 0

Exogenous glucose storage (total glucose disposal minus exogenous glycolytic flux) appeared higher in the diabetic patients during baseline measurements $(p<0.08)$, and was highly significantly lower in diabetic patients during insulin infusion (Table 2). Non-oxidative glucose metabolism (total glucose disposal minus glucose oxidation) was significantly elevated in the NIDDM patients during baseline measurements and markedly decreased during insulin infusion (Table 2). Insulin significantly increased glucose oxidation and exogenous glycolytic flux rates, and decreased lipid oxidation, in both NIDDM patients and control subjects (Table 2). Furthermore, insulin significantly decreased HGP in both study groups. However, in contrast to the control subjects, insulin did not significantly increase non-oxidative glucose metabolism or exogenous glucose storage in the NIDDM patients (Table 2).

The rate of exogenous glycolytic flux correlated positively with the rate of whole body glucose oxidation in the diabetic subjects during clamp insulin infusion $(R=0.69 ; p<0.05)$, but not in group of control subjects $(R=0.41$; NS). The correlations between glycolytic flux and whole body glucose oxidation did not reach statistical significance in the diabetic patients $(R=0.55$; NS) or in control subjects $(R=0.24$; NS) during basal measurements. When the two groups were considered together $(n=20)$, the exogenous glycolytic flux rate and the glucose oxidation rate correlated significantly during clamp insulin infusion ( $R=0.73 ; p<0.0005)$, but not during baseline measurements $(R=0.27$; NS). 
The exogenous glycolytic flux rate correlated inversely with the rate of lipid oxidation rate in the diabetic patients during baseline measurements $(R=$ $-0.66 ; p<0.05$ ) (Fig. 3 ), and tended to do so also during insulin infusion $(R=-0.44 ; \mathrm{NS})$ (Fig. 3$)$. In the control subjects, a similar inverse correlation was noted during insulin infusion $(R=-0.65 ; p<0.05)$ (Fig. 3), but not during baseline determinations $(R=0.51$; NS) (Fig. 3). When the groups of NIDDM patients and control subjects were considered together $(n=20)$, the rate of exogenous glycolytic flux correlated inversely with the lipid oxidation rate during insulin infusion $(R=-0.79 ; p<0.00005)$, but not during baseline measurements $(R=0.04 ; \mathrm{NS})$ (Fig. 3 ).

Rates of whole body glucose and lipid oxidation as determined using indirect calorimetry correlated inversely in diabetic patients in the basal state $(R=$ $-0.64 ; p<0.05$ ) (Fig. 3) and during clamp insulin infusion $(R=0.75 ; p<0.02)$ (Fig. 3 ). In the control subjects, glucose- and lipid oxidation rates correlated inversely during clamp insulin infusion $(R=-0.71$; $p<0.03$ ) (Fig. 3), but not during baseline measurements $(R=0.26$; NS). When NIDDM patients and control subjects were considered together $(n=20)$, glucose and lipid oxidation rates correlated inversely highly significantly during insulin infusion $(R=$ $-0.90 ; p<0.00001$ ) (Fig. 3), but not during baseline measurements ( $R=0.38$; NS) (Fig. 3 ).

Table 3 demonstrates that the response to insulin (insulin-stimulated minus baseline measurements) of the various parameters of glucose and lipid metabolism listed in Table 2. Total peripheral glucose uptake, exogenous glycolytic flux, non-oxidative glucose uptake, exogenous glucose storage and glucose oxidation rates were all significantly decreased (insulin-resistant) in diabetic patients compared with control subjects. However, the suppressive effect of insulin on HGP and lipid oxidation rates was similar in diabetic patients and control subjects.

Total body energy expenditure was significantly higher in the diabetic patients during baseline determinations (5562 \pm 312 vs $4737 \pm 158 \mathrm{~J} / \mathrm{min} ; p=0.05$ ). During insulin infusion, however, rates of energy expenditure were similar in diabetic patients and control subjects ( $5263 \pm 286$ vs $4856 \pm 193 \mathrm{~J} / \mathrm{min}$; NS).

During baseline measurements fractional glycogen synthase activities at 0 and $0.1 \mathrm{mmol} / \mathrm{l} \mathrm{G} 6 \mathrm{P}$ were similar in diabetic patients compared with control subjects (Table 4). However, the incremental insulin activation of fractional GS activities was significantly lower in diabetic patients compared with control subjects (Table 4). Glycogen synthase activities measured at $10 \mathrm{mmol} / 1 \mathrm{G} 6 \mathrm{P}$ with either low $(0.31 \mathrm{mmol} / \mathrm{l})$ or high ( $5 \mathrm{mmol} / \mathrm{l}$ ) UDPG concentrations (total glycogen synthase activities) did not differ between diabetic patients and control subjects during baseline measurements, or during insulin infusion (Table 4).

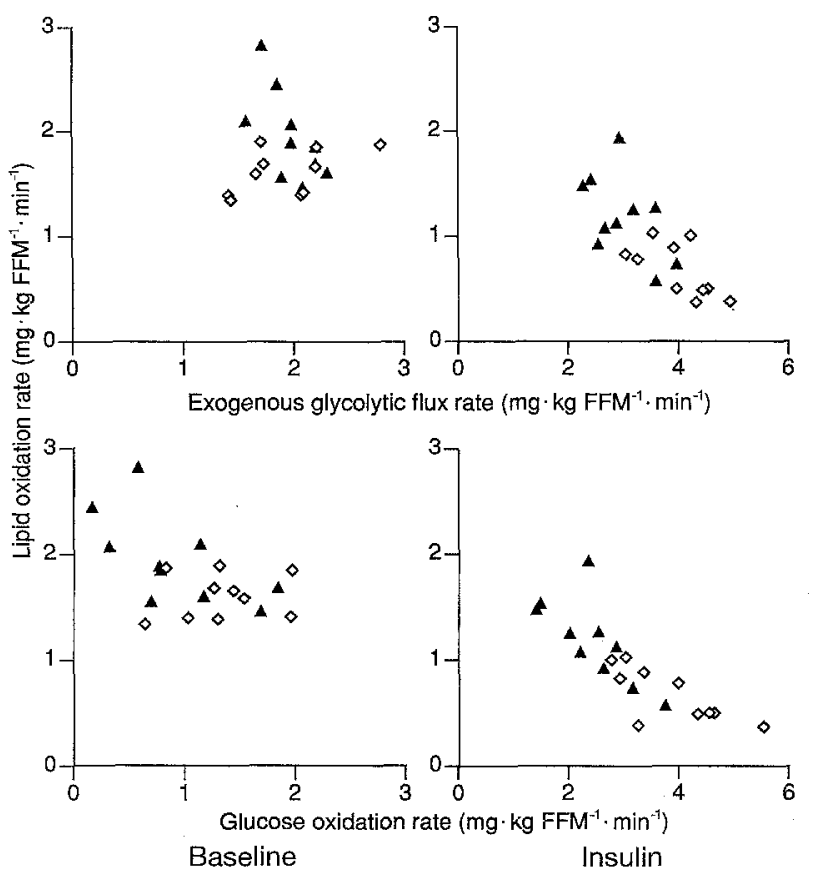

Fig. 3. Relationship between lipid oxidation rates and exogenous glycolytic flux rates (upper panels) and lipid and glucose oxidation rates (lower panels) during baseline determinations and during insulin infusion in NIDDM patients $(\boldsymbol{A})$ and control subjects $(\diamond)$. Correlation coefficients as follows:

\begin{tabular}{|c|c|c|c|c|c|}
\hline \multirow{2}{*}{\multicolumn{2}{|c|}{$\begin{array}{l}\text { Correlation of lipid } \\
\text { oxidation rate vs: }\end{array}$}} & \multicolumn{2}{|c|}{$\begin{array}{l}\text { Exogenous } \\
\text { glycolytic rate }\end{array}$} & \multicolumn{2}{|c|}{$\begin{array}{l}\text { Glucose } \\
\text { oxidation rate }\end{array}$} \\
\hline & & & $p$ value & & $p$ value \\
\hline \multirow[t]{3}{*}{ Baseline } & NIDDM & -0.66 & $<0.05$ & -0.64 & $<0.05$ \\
\hline & & $051^{\circ}$ & NS & 026 & \\
\hline & $\operatorname{All}(n=20)$ & 0.04 & NS & 0.38 ; & NS \\
\hline \multirow[t]{3}{*}{ Insulin } & NIDDM & -0.44 & NS & -0.75 & $<0.02$ \\
\hline & $\begin{array}{l}\text { Control } \\
\text { subjects }\end{array}$ & & & & \\
\hline & All $(n=20)$ & -0.79 & $<0.00005$ & -0.90 & $<0.00001$ \\
\hline
\end{tabular}

\section{Discussion}

The overall aim of the present study was to examine glucose and lipid metabolism in NIDDM patients during an experimental fasting euglycaemic equilibrium state, in order to gain insight into the mechanism(s) responsible for the development of the variable fasting and postprandial hyperglycaemia observed daily in NIDDM patients. In particular we wanted to determine the potential site(s) and contributions of the various intracellular metabolic pathways governing the in vivo partitioning of glucose utilization in NIDDM subjects during periods of low fasting normo-(or eu-) insulinaemia and physiologic hyperinsulinaemia. Thus, with the current experimental design (insulin infusion to normalize fasting hyperglycaemia followed by insulin withdrawal), initial normoglycaemia was achieved in NIDDM subjects (Fig. 1). However, plas- 
Table 3. In vivo response of glucose and lipid turnover rates to insulin in NIDDM patients $(n=10)$ and matched control subjects $(n=10)$.

\begin{tabular}{lccl}
\hline & NIDDM & Control subjects & $p$-value \\
\hline $\begin{array}{l}\text { Hepatic glucose } \\
\text { production rate }\end{array}$ & $-2.62 \pm 0.19$ & $-2.28 \pm 0.34$ & $\mathrm{NS}$ \\
$\begin{array}{l}\text { Glucose uptake } \\
\text { rate }\end{array}$ & $2.04 \pm 0.76$ & $9.14 \pm 1.15$ & $<0.001$ \\
$\begin{array}{l}\text { Exogenous } \\
\text { glycolytic }\end{array}$ & $1.04 \pm 0.19$ & $2.10 \pm 0.24$ & $<0.02$ \\
flux rate & $1.54 \pm 0.24$ & $2.52 \pm 0.26$ & $<0.02$ \\
$\begin{array}{l}\text { Glucose } \\
\text { oxidation rate }\end{array}$ & & & \\
$\begin{array}{l}\text { Non-oxidative } \\
\text { glucose uptake }\end{array}$ & $0.51 \pm 0.82$ & $6.61 \pm 1.08$ & $<0.0001$ \\
$\begin{array}{l}\text { rate } \\
\begin{array}{l}\text { Exogenous } \\
\text { glucose } \\
\text { storage rate }\end{array}\end{array}$ & $1.02 \pm 0.91$ & $7.04 \pm 1.10$ & $<0.0001$ \\
$\begin{array}{l}\text { Lipid } \\
\text { oxidation rate }\end{array}$ & $-0.77 \pm 0.10$ & $-0.94 \pm 0.12$ & $\mathrm{NS}$ \\
\hline
\end{tabular}

Baseline values were subtracted from insulin-stimulated values in order to evaluate the in vivo insulin sensitivity (responsiveness) of the various parameters. All data of both lipid oxidation and glucose turn over rates are expressed as $\mathrm{mg} \cdot \mathrm{kg}$ $\mathrm{FFM}^{-1} \cdot \mathrm{min}^{-1}$. Data are mean $\pm \mathrm{SEM}$

ma glucose concentration rose steadily in the fasting NIDDM subjects during the period of insulin with drawal, which allowed us to determine which defect(s) of glucose metabolism was responsible for the re-establishment of fasting hyperglycaemia.
Firstly, in the basal iatrogenic-induced euglycaemic state an increased rate of HGP seemed to be the cause of the spontaneously increasing plasma glucose concentration in the NIDDM patients. Thus, while HGP was significantly elevated, no decrease in the rate of peripheral glucose uptake was detected in the NIDDM patients. In contrast, the rate of peripheral glucose uptake was actually increased in the NIDDM patients during the low basal plasma insulin concentrations. This finding is consistent with an elevated baseline glucose turnover rate which, in the presence of the spontaneously increasing plasma glucose concentration in the NIDDM patients may appear somewhat paradoxical. However, from the measurements of indirect calorimetry, exogenous glycolytic flux and skeletal muscle glycogen synthase activities it was possible to characterize the intracellular partitioning of the increased glucose turnover in the basal state in the NIDDM patients. Thus, the increased glucose uptake during the baseline equilibrium period with low plasma insulin concentrations was due to an increased non-oxidative glucose uptake, which in turn was not explained solely by the non-significantly elevated exogenous glucose storage or skeletal muscle glycogen synthase activity in the NIDDM patients. Therefore, the increased non-oxidative glucose uptake was possibly (at least partly) due to an elevated rate of non-oxidative glycolytic flux, although the current methodologies did not allow such accurate in vivo measurements during low basal plasma insulin concentrations (see Methods section). On the other hand, the raised baseline plas-

Table 4. Activities of skeletal muscle glycogen synthase in NIDDM patients $(n=10)$ and matched control subjects $(n=10)$

\begin{tabular}{|c|c|c|c|c|}
\hline Glycogen synthase activity & & NIDDM & Control subjects & $p$-value \\
\hline$(0.0 \mathrm{mmol} / 1 \mathrm{G} 6 \mathrm{P})$ & $\begin{array}{l}\text { Baseline } \\
\text { Insulin }\end{array}$ & $\begin{array}{l}0.35 \pm 0.09 \\
0.73 \pm 0.20^{\mathrm{a}}\end{array}$ & $\begin{array}{l}0.27 \pm 0.07 \\
0.77 \pm 0.14^{\mathrm{a}}\end{array}$ & $\begin{array}{l}\text { NS } \\
\text { NS }\end{array}$ \\
\hline$(10 \mathrm{mmol} / \mathrm{l} \mathrm{G} 6 \mathrm{P})$ & $\begin{array}{l}\text { Baseline } \\
\text { Insulin }\end{array}$ & $\begin{array}{l}5.85 \pm 0.95 \\
5.79 \pm 0.70\end{array}$ & $\begin{array}{l}6.32 \pm 0.64 \\
6.01 \pm 0.66\end{array}$ & $\begin{array}{l}\text { NS } \\
\text { NS }\end{array}$ \\
\hline FV $0.0(\%)$ & $\begin{array}{l}\text { Baseline } \\
\text { Insulin }\end{array}$ & $\begin{array}{l}6.2 \pm 0.8 \\
12.7 \pm 3.0^{b}\end{array}$ & $\begin{array}{l}4.2 \pm 0.6 \\
13.0 \pm 1.6^{\mathrm{b}}\end{array}$ & $\begin{array}{l}\text { NS } \\
\text { NS }\end{array}$ \\
\hline FV $0.1(\%)$ & $\begin{array}{l}\text { Baseline } \\
\text { Insulin }\end{array}$ & $\begin{array}{l}29.3 \pm 2.4 \\
50.3 \pm 5.1^{b}\end{array}$ & $\begin{array}{l}26.7 \pm 1.7 \\
57.0 \pm 2.3^{b}\end{array}$ & $\begin{array}{l}\mathrm{NS} \\
\mathrm{NS}\end{array}$ \\
\hline $\begin{array}{l}\triangle \mathrm{FV} 0.0(\%) \\
\Delta \mathrm{FV} 0.1(\%)\end{array}$ & & $\begin{array}{l}6.5 \pm 2.5 \\
16.4 \pm 3.9\end{array}$ & $\begin{array}{l}8.8 \pm 1.0 \\
26.5 \pm 1.7\end{array}$ & $\begin{array}{l}<0.05 \\
<0.05\end{array}$ \\
\hline
\end{tabular}

Biopsies were taken from the vastus lateralis muscle in the basal fasting equilibrium state and after $+180 \mathrm{~min}$ insulin infusion $\left(40 \mathrm{mU} \cdot \mathrm{m}^{-2} \cdot \mathrm{min}^{-1}\right)$. Baseline muscle biopsies in the NIDDM patients were taken $150 \mathrm{~min}$ after the withdrawal of a prior i.v. insulin infusion given to normalize the plasma glucose concentration. Glycogen synthase activities are given as nmol UDPglucose incorporated into glycogen per mg extract protein per min. Glycogen synthase activities were measured in the absence of its allosteric modulator glucose 6-phosphate $(0.0$ $\mathrm{mmol} / \mathrm{G} \mathrm{G} 6 \mathrm{P})$, in the presence of a physiologic G6P concentration $(0.1 \mathrm{mmol} / \mathrm{l})$, and in the presence of a maximal stimulatory $\mathrm{G} 6 \mathrm{P}$ concentration $(10 \mathrm{mmol} / \mathrm{l})$. In addition, glycogen synthase activities were measured in the presence of $10 \mathrm{mmol} / \mathrm{l} \mathrm{G} 6 \mathrm{P}$ and a maximal stimulatory UDP-glucose concentration of $5 \mathrm{mmol} /$ 1 to estimate the total enzyme activities. Fractional velocities $(\mathrm{FV})$ are given in \%. $\Delta \mathrm{FV}$ values are insulin-stimulated increments in fractional velocities over basal values. $p<0.05$ vs baseline determinations; $p<0.002$ vs baseline determinations 
ma lactate concentration does support the notion of an elevated baseline non-oxidative glycolytic flux in the NIDDM patients. In contrast, the glucose oxidation rate was significantly decreased, and the lipid oxidation rate correspondingly increased, in the NIDDM patients during the low baseline plasma insulin levels. Thus, the data demonstrate that the glucose-fatty acid cycle, as previously outlined by Randle and co-workers [38], operates during the low insulin equilibrium state of NIDDM, and that this interaction may also contribute to the development of fasting hyperglycaemia in NIDDM.

Therefore, the sequence of events in the basal equilibrium low insulinemic state could theoretically be: an increased rate of lipid oxidation may be due to either an increased tissue fat content (higher waist to hip ratio), or perhaps due to a relative insufficient tissue insulin suppression of lipolysis (insulin deficiency or insulin resistance); an increased rate of lipid oxidation may then inhibit glucose oxidation at the level of pyruvate dehydrogenase [39]; this in turn may theoretically direct basal intracellular glucose flux toward increased non-oxidative glycolytic flux, and finally an increased release of lactate from tissues causing increased plasma lactate levels, which then serves as a substrate for the hepatic gluconeogenesis. This sequence of events is referred to as the Cori cycle [40], and is supported by previous findings in NIDDM patients of increased rates of $1{ }^{13} \mathrm{C}$-glucose recycling [41] and hepatic gluconeogenesis from lactate [42]. However, some of the increased plasma lactate concentrations basally in the present study may reflect the metabolic effect of the prior insulin infusion employed from -210 to -150 min. Thus, our data do not allow us to establish whether the increased HGP or the abnormal intracellular partitioning of the peripheral glucose flux is the primary driving force behind the elevated baseline Cori cycle and glucose turnover rate. Nevertheless, it is of great pathophysiological interest that the abnormalities of the hepatic and peripheral glucose processing seem to work together in causing and maintaining fasting hyperglycaemia in NIDDM patients as suggested recently [43].

The present data do not support a direct role for decreased skeletal muscle glycogen synthesis in the maintenance (or cause) of fasting hyperglycaemia in NIDDM patients. Thus, both the rates of isotopically determined exogenous glucose storage and skeletal muscle fractional glycogen synthase activities appeared higher in the NIDDM patients during baseline determinations, although neither of the two independent measurements of baseline glycogen synthesis reached statistical significance compared with the control subjects or in fact correlated significantly with each other in the NIDDM patients. However, a decreased glucose storage (and skeletal muscle glycogen synthase activity) was quantitatively the most pronounced defect of glucose metabolism during the physiological clamp insulin infusion (Table 4), indicating a major role for this defect in the development of hyperglycaemia in NIDDM patients during hyperinsulinaemic postprandial situations. Thus, the measurements of exogenous glycolytic flux, and thereby indirectly exogenous glucose storage rates during insulin infusion in the present study confirm the data recently published by Del Prato et al. [12] using similar in vivo techniques albeit somewhat lower clamp insulin levels, and extend the conclusions from other previous muscle biopsy [14. 17] and in vivo nuclear magnetic resonance [15] determinations, that the decreased insulin-stimulated non-oxidative glucose disposal (as determined using indirect calorimetry) in NIDDM patients is almost solely due to a decreased skeletal muscle glycogen synthesis, and especially not to a decreased non-oxidative glycolytic flux. In that context, it should also be noted that the abnormalities of glucose metabolism demonstrated in this study during acute manipulations of the plasma glucose concentration are of major importance for our understanding of the mechanisms responsible for the maintenance of hyperglycaemia in patients with frank NIDDM with an impaired insulin secretion pattern. However, the data may not necessarily be extrapolated to the natural history of NIDDM from the pre-diabetic stage to frank NIDDM, which is a very slow and possibly life-long process. Specifically, despite the absence of any clinical or chemical hypoglycaemic episodes, we cannot totally exclude the possibility that the secretion of counter-regulatory hormones might have been stimulated by the prior insulin infusion in the NIDDM subjects, and that this may have influenced the results obtained in the present study.

The presence of insulin resistance in NIDDM patients is beyond dispute [1-3]. In the present study, we found that peripheral insulin resistance was present in the NIDDM patients in all of the major pathways of intracellular glucose metabolism which included glycogen synthesis (and muscle glycogen synthase activation), exogenous glycolytic flux and glucose oxidation, whereas no insulin resistance was detectable at the levels of suppression of lipid oxidation or HGP (Table 3). In addition, suppression of non-oxidative glycolytic flux appeared blunted in the NIDDM patients (Table 2). Thus, the rate of non-oxidative glycolytic flux appeared higher in the NIDDM patients during hyperinsulinaemia and was, in contrast to the control subjects not completely suppressed during insulin infusion (Table 2). This is in agreement with the finding by Del Prato et al. [12] of a disproportionately elevated rate of non-oxidative glycolytic flux in NIDDM patients during somewhat lower clamp insulin infusion rates, and demonstrates an unequal intracellular processing of the glucose that has been transported into the cell in the NIDDM subjects compared with control subjects. Thus, the study supports the conclusion also reached 
by Del Prato et al. [12] that the defects of peripheral glucose metabolism in NIDDM go beyond the process of glucose transport across the cell membrane. However, it should be noted that this does not exclude the presence of an independent (primary or secondary) defect at the level of the membrane glucose transporter system in NIDDM patients.

Our study does not answer the important question concerning the cause(s) of the insulin resistance in the two major pathways of glucose metabolism in the NIDDM patients. However, the inverse relationships between lipid oxidation and glucose oxidation rates (and also exogenous glycolytic flux) (Fig.3) during both low and high plasma insulin concentrations support a role for elevated plasma and tissue NEFA concentrations, and the glucose-fatty acid cycle as outlined above. There are also data to support that elevated plasma and tissue NEFA concentrations may be involved in causing the insulin resistance in the quantitatively most important pathway of skeletal muscle glucose metabolism, glycogen synthesis [4446]. However, recent data from our laboratory [16] and others [17-19] indicate a role for a genetically determined defect of skeletal muscle glycogen synthase activation in NIDDM patients.

Using indirect calorimetry, an increased rate of gluconeogenesis from amino acids may erroneously be measured and misinterpreted as a decreased rate of glucose oxidation $(23,24)$. However, in the present study the finding of a decreased glucose oxidation rate in the NIDDM patients during insulin infusion was supported and confirmed by a decreased rate of exogenous glycolysis, and a statistical significantly correlation between those two parameters. Nevertheless, we cannot exclude the theoretical possibility that the decreased baseline glucose oxidation rate as determined using indirect calorimetry, and thereby also to some extent the increased baseline non-oxidative glucose uptake rate could partly be due to an increased rate of gluconeogenesis from amino acids in the NIDDM patients.

In conclusion, the present study demonstrates that multiple defects of both hepatic and peripheral glucose processing are involved in the development of hyperglycaemia in NIDDM patients. A disproportionately high rate of HGP is the major determinant of hyperglycaemia during low plasma insulin concentrations, whereas a decreased peripheral (muscle) glucose uptake, oxidation and especially storage (skeletal muscle glycogen synthase activation) are the quantitatively major defects during higher plasma insulin concentrations. Measurements of non-oxidative glycolytic flux rates during hyperinsulinaemia demonstrated a higher rate in the NIDDM patients. Furthermore, plasma lactate concentrations were elevated in the NIDDM patients during low plasma insulin concentrations. This, combined with a higher rate of lipid oxidation and a concomitant lower rate of whole body glucose oxidation during both the low and high physiological plasma insulin concentrations, suggests a role for both the glucose-fatty cycle and the Cori acid cycle in the development and maintenance of hyperglycaemia in the NIDDM patients. Finally, the data indicate that the defect(s) of peripheral (skeletal muscle) glucose processing in NIDDM goes beyond the process of glucose transport across the cell membrane.

Acknowledgements. The authors would like to acknowledge the expert technical assistance of Ms. K. Dyregaard, Ms. H. Vorup, Ms. C. Fage Larsen, and Mrs. H. Hansen. The study was supported by grants from the Danish Medical Research Council, the Danish Diabetes Association, the Novo Foundation, the Velux Foundation, the Clinical Research Institute, Odense University Hospital, and from the Diabetes Australia Research Foundation and the Hoechst (Australia) Research Foundation.

\section{References}

1. Gerich JE (1991) Is muscle the major site of insulin resistance in type 2 (non-insulin-dependent) diabetes mellitus? Diabetologia 34:607-610

2. DeFronzo RA (1992) Pathogenesis of type 2 (non-insulin dependent) diabetes mellitus: a balanced overview. Diabetologia 35:389-397

3. Beck-Nielsen $\mathrm{H}$, Hother-Nielsen O, Vaag A, Alford F (1994) Pathogenesis of type 2 diabetes mellitus (NIDDM): the role of skeletal muscle glucose uptake and hepatic glucose production in the development of hyperglycaemia. A critical comment. Diabetologia 37(2):217-221

4. Hother Nielsen O, Beck-Nielsen H (1990) On the determination of basal glucose production rate in patients with type 2 (non-insulin- dependent) diabetes mellitus using primed-continuous $3-{ }^{3} \mathrm{H}$-glucose infusion. Diabetologia 33:603-610

5. Vaag A, Damsbo P, Hother-Nielsen O, Beck-Nielsen $H$ (1992) Hyperglycaemia compensates for the defects in insulin-mediated glucose metabolism and in the activation of glycogen synthase in the skeletal muscle of patients with type 2 (non-insulin-dependent) diabetes mellitus. Diabetologia 35:80-88

6. Halter JB, Graf RJ, Porte DJ (1979) Potentiation of insulin secretory responses by plasma glucose levels in man: evidence that hyperglycaemia in diabetes compensates for impaired glucose potentiation. J Clin Endocrinol Metab 48:946-954

7. Vaag A, Hother-Nielsen O, Skött P, Andersen P, Richter EA, Beck-Nielsen H (1992) Effect of acute hyperglycaemia on glucose metabolism in skeletal muscles in IDDM patients. Diabetes 41:174-182

8. Hother Nielsen O, Vaag A, Skott P, Beck Nielsen H (1993) Effect of hyperglycaemia per se on glucose turnover rates in patients with insulin-dependent diabetes. Metabolism 42:86-93

9. Gray RS, Scarlett JA, Griffin J, Olefsky JM, Kolterman OG (1982) In vivo deactivation of peripheral, hepatic, and pancreatic insulin action in man. Diabetes 31:929-936

10. Rossetti L, Giaccari A (1990) Relative contribution of glycogen synthesis and glycolysis to insulin-mediated glucose uptake. A dose-response euglycaemic clamp study in normal and diabetic rats. J Clin Invest 85:1785-1792 
11. Christopher MJ, Rantzau C, Ward GM, Alford FP (1994) Impact of variable insulinaemia and glycemia on in vivo glycolysis and glucose storage in dogs. Am J Physiol (Endocrinol Metab) 266 (29):E62-E71

12. Del Prato S, Bonadonna RC, Bonora E, et al. (1993) Characterization of cellular defects of insulin action in Type 2 (non- insulin-dependent) diabetes mellitus. J Clin Invest 91(2):484-494

13. Rossetti L, Lee Y-T, Rutz J, Aldridge SC, Shamoon H, Boden G (1993) Quantitation of glycolysis and skeletal muscle glycogen synthesis in humans. Am J Physiol (Endocrinol Metab) 265 (28):E761-E769

14. Damsbo P, Vaag A, Hother-Nielsen O, Beck-Nielsen H (1991) Reduced glycogen synthase activity in skeletal muscle from obese patients with and without type 2 (non-insulin-dependent) diabetes mellitus. Diabetologia 34:239-245

15. Shulman GI, Rothman DL, Jue T, Stein P, DeFronzo RA, Shulman RG (1990) Quantitation of muscle glycogen synthesis in normal subjects and subjects with non-insulindependent diabetes by $13 \mathrm{C}$ nuclear magnetic resonance spectroscopy. N Eng1 J Med 322:223-228

16. Vaag A, Henriksen JE, Beck Nielsen H (1992) Decreased insulin activation of glycogen synthase in skeletal muscles in young nonobese Caucasian first-degree relatives of patients with non-insulin- dependent diabetes mellitus. J Clin Invest 89:782-788

17. Schalin Jantti C, Harkonen M, Groop LC (1992) Impaired activation of glycogen synthase in people at increased risk for developing NIDDM. Diabetes 41:598-604

18. Wells AM, Sutcliffe IC, Johnson AB, Taylor R (1993) Abnormal activation of glycogen synthesis in fibroblasts from NIDDM subjects. Evidence for an abnormality specific to glucose metabolism. Diabetes 42:583-589

19. Groop LC, Kankuri M, Schalin Jantti C, et al. (1993) Association between polymorphism of the glycogen synthase gene and non- insulin-dependent diabetes mellitus. N Engl J Med 328:10-14

20. McGuire EA, Helderman JH, Tobin JD, Andres R, Berman M (1976) Effects of arterial versus venous sampling on analysis of glucose kinetics in man. J Appl Physiol 41:565-573

21. DeFronzo RA, Tobin JD, Andres R (1979) Glucose clamp technique: a method for quantifying insulin secretion and resistance. Am J Physiol 237:E214-E223

22. Molina JM, Baron AD, Edelman SV, Brechtel G, Wallace P, Olefsky JM (1990) Use of a variable tracer infusion method to determine glucose turnover in humans. Am J Physiol 258:E16-E23

23. Frayn KN (1983) Calculation of substrate oxidation rates in vivo from gaseous exchange. J Appl Physiol 55:628-634

24. Ferrannini E (1983) The theoretical basis of indirect calorimetry: a review. Metabolism 37:287-301

25. Tappy L, Owen OE, Boden G (1988) Effect of hyperinsulinaemia on urea pool size and substrate oxidation rates. Diabetes 37:1212-1216

26. Steele R (1959) Influence of glucose loading and of injected insulin on hepatic glucose output. Ann N Y Acad Sci $82: 420-430$

27. Cowan JS, Hetenyi GJ (1971) Glucoregulatory responses in normal and diabetic dogs recorded by a new tracer method. Metabolism 20:360-372

28. Bell PM, Firth RG, Rizza RA (1986) Effects of hyperglycaemia on glucose production and utilization in humans. Measurement with $\left[2^{3} \mathrm{H}\right]-,\left[3^{3} \mathrm{H}\right]$-, and $\left[6^{14} \mathrm{C}\right]$ glucose. Diabetes 35:642-648

29. Hostler KY, Landau BR (1967) Estimation of the pentose cycle contribution to glucose metabolism in tissue in vivo. Biochemestry 6:2961-2964
30. Karlander S, Roovete A, Vranic M, Efendic S (1986) Glucose and fructose 6-phosphate cycle in humans. Am J Physiol 251:E530-E536

31. Spence JT, Koudelka AP (1985) Pathway of glycogen synthesis from glucose in hepatocytes maintained in primary culture. J Biol Chem 260:1521-1526

32. Lukaski HC, Johnson PE, Bolonchuk WW, Lykken GI (1985) Assessment of fat-free mass using bioelectrical impedance measurements of the human body. Am J Clin Nutr 41:810-817

33. Butler PC, Kryshak EJ, Marsh M, Rizza RA (1990) Effect of insulin on oxidation of intracellularly and extracellularly derived glucose in patients with NIDDM. Evidence for primary defect in glucose transport and/or phosphorylation but not oxidation. Diabetes 39:1373-1380

34. Mandarino LJ, Wright KS, Verity LS, et al. (1987) Effects of insulin infusion on human skeletal muscle pyruvate dehydrogenase, phosphofructokinase, and glycogen synthase. Evidence for their role in oxidative and nonoxidative glucose metabolism. J Clin Invest 80:655-663

35. Thomas JA, Schlender KK, Larner J (1968) A rapid filter paper assay for UDPglucose-glycogen glucosyltransferase, including an improved biosynthesis of UDP- ${ }^{14} \mathrm{C}$-glucose. Anal Biochem 25:486-499

36. Itaya K, Ui M (1965) Colorimetric determination of free fatty acids in biological fluids. J Lipid Res 6:16-20

37. Passonneau JV (1974) L-( + )-lactate. Flouroetric method. In: Bergmeyer HV (ed) Methods of enzymatic analysis. Academic Press, New York, pp 1468-1472

38. Randle PJ, Garland PB, Hales CN, Newsholme EA (1963) The glucose fatty-acid cycle. Its role in insulin sensitivity and the metabolic disturbances of diabetes mellitus. Lancet 1:785-789

39. Vaag A, Handberg A, Skött P, Richter EA, Beck-Nielsen H (1994) Glucose-fatty acid cycle operates in humans at the levels of both whole body and skeletal muscle during low and high physiological plasma insulin concentrations. Eur J Endocrinol 130:70-79

40. Cori CF (1931) Mammalian carbohydrate metabolism. Physiol Rev 11:143-275

41. Zawadzki JK, Wolfe RR, Mott DM, Lillioja S, Howard BV, Bogardus C (1988) Increased rate of Cori cycle in obese subjects with NIDDM and effect of weight reduction. Diabetes 37:154-159

42. Consoli A, Nurjhan N, Reilly JJJ, Bier DM, Gerich JE (1990) Mechanism of increased gluconeogenesis in noninsulin-dependent diabetes mellitus. Role of alterations in systemic, hepatic, and muscle lactate and alanine metabolism. J Clin Invest 86:2038-2045

43. Vranic M (1992) Banting Lecture: glucose turnover. A key to understanding the pathogenesis of diabetes (indirect effects of insulin). Diabetes 41:1188-1206

44. Argyraki M, Wright PD, Venables CW, Proud G, Taylor R (1989) In vitro study of human skeletal muscle strips: effect of nonesterified fatty acid supply on glucose storage. Metabolism 38:1183-1187

45. Boden G, Jadali F, White J, et al. (1991) Effects of fat on insulin-stimulated carbohydrate metabolism in normal men. J Clin Invest 88:960-966

46. Vaag A, Skott P, Damsbo P, Gall MA, Richter EA, BeckNielsen H (1991) Effect of the antilipolytic nicotinic acid analogue acipimox on whole-body and skeletal muscle glucose metabolism in patients with non-insulin-dependent diabetes mellitus. J Clin Invest 88:1282-1290 